\title{
Clinical Study \\ Predictors of Metabolic Syndrome in Participants of a Cardiac Rehabilitation Program
}

\author{
Alejandra Farias Godoy, ${ }^{1}$ Andrew Ignaszewski, ${ }^{2}$ Jiri Frohlich, ${ }^{2}$ and Scott A. Lear ${ }^{1,2,3}$ \\ ${ }^{1}$ Department of Biomedical Physiology and Kinesiology, Simon Fraser University, Burnaby, BC, Canada V5A 156 \\ ${ }^{2}$ Healthy Heart Program, St. Paul's Hospital, Providence Health Care, Vancouver, BC, Canada V6Z 1 Y6 \\ ${ }^{3}$ Faculty of Health Sciences, Simon Fraser University, Harbour Centre Campus, Vancouver, BC, Canada V6B 5K3
}

Correspondence should be addressed to Scott A. Lear, slear@providencehealth.bc.ca

Received 12 December 2011; Accepted 19 January 2012

Academic Editor: A. Bobik

Copyright (C) 2012 Alejandra Farias Godoy et al. This is an open access article distributed under the Creative Commons Attribution License, which permits unrestricted use, distribution, and reproduction in any medium, provided the original work is properly cited.

Metabolic syndrome increases the risk of all-cause mortality, cardiovascular mortality and cardiovascular events in patients with cardiovascular disease (CVD). This study assessed the predictors of metabolic syndrome, both its incidence and resolution in a cohort of cardiac rehabilitation program graduates. Methods. A total of 154 and 80 participants without and with metabolic syndrome respectively were followed for 48 months. Anthropometric measurements, metabolic risk factors, and quality of life were assessed at baseline and at 48 months. Logistic regression models were used to assess the predictors of metabolic syndrome onset and resolution. Results. Increasing waist circumference (OR 1.175, $P \leq 0.001$ ) was an independent predictor for incident metabolic syndrome $\left(R^{2}\right.$ for model $\left.=0.46\right)$. Increasing waist circumference $(\mathrm{OR} 1.234, P \leq 0.001)$, decreasing HDL-C $(\mathrm{OR} 0.027, P=0.005)$, and increasing triglycerides (OR 3.005, $P=0.003$ ) were predictors of metabolic syndrome resolution. Conclusion. Patients with CVD that further develop metabolic syndrome are particularly susceptible for the cascade of cardiovascular events and mortality. Increasing waist circumference confers a higher risk for future onset of metabolic syndrome in this group of patients. They will require closer follow-up and should be targeted for further prevention strategies after cardiac rehabilitation program completion.

\section{Introduction}

The metabolic syndrome (MetS) is a prothrombotic, proinflammatory state characterized by abdominal obesity, insulin resistance/hyperinsulinemia (leading to elevated plasma glucose), elevated blood pressure (BP) and dyslipidemia (high triglycerides, low-high-density lipoprotein [HDL-C] with preponderance of small-dense, low-density lipoprotein [LDL-C] particles) [1]. These metabolic changes are associated with the development and progression of diabetes and coronary artery disease [2,3]. Previous studies have reported that for patients with cardiovascular disease (CVD), MetS confers an even greater risk for cardiovascular events, including cardiovascular and all-cause mortality than those without MetS [4-7]. For example, MetS risk estimates for allcause and cardiovascular mortality were reported to be greatest in a population with existing CVD compared to those without CVD (HR 1.47 versus 1.06, HR 2.53 versus 2.01,
$P<0.05$, resp.) [5]. Likewise, the presence of MetS in women with suspected coronary artery disease confers a significantly higher risk for cardiovascular events than in those with normal metabolic status (HR 4.93 versus $1.41, P=0.05$ ) [6]. As there is a synergistic effect between MetS and CVD on cardiovascular morbidity and mortality [7], these patients are at especially high risk, and it is therefore important to identify MetS in patients with CVD as well as find the best predictors of it.

Cardiac rehabilitation programs (CRPs) are uniquely positioned to assess the presence of MetS and are a proven intervention in reducing CVD risk [8-10]. The purpose of this study was to identify predictors of MetS in a cohort of men and women with CVD free of MetS, over a fouryear period following completion of their CRP. We also assessed predictors of MetS resolution in men and women with both CVD and MetS over the same time period. Specific attention was placed on identifying predictors that 
can be easily measured outside of the CRP environment and readily available at the health care provider's office without substantial additional cost.

\section{Methods}

We used data from the Extensive Lifestyle Intervention (ELMI) Trial in which a total of 302 men and women with ischemic heart disease were recruited following completion of a standard CRP for a four-year study [11]. The ELMI Trial was a randomized study to test the effectiveness of a modest intervention of additional exercise sessions, telephone follow-up, and risk factor and lifestyle counselling compared to usual care. For the current analysis, the two groups have been combined and analyzed together as there were no differences between the two groups in outcomes relevant to the current investigation.

The MetS was defined according to the most recently published harmonized criteria by the International Diabetes Federation in conjunction with the National Heart, Lung, and Blood Institute, American Heart Association, World Heart Federation, International Atherosclerosis Society, and International Association for the Study of Obesity [12]. Participants were classified as having MetS at CRP completion and at 48 months if they had three out of the following five criteria: triglycerides $\geq 1.7 \mathrm{mmol} / \mathrm{L}$, HDL$\mathrm{C}<1.00 \mathrm{mmol} / \mathrm{L}$ for men and $<1.30 \mathrm{mmol} / \mathrm{L}$ for women or specific treatment for these lipid abnormalities, $\mathrm{BP} \geq$ $130 / 85 \mathrm{mmHg}$ or specific treatment of diagnosed hypertension, fasting plasma glucose $\geq 5.6 \mathrm{mmol} / \mathrm{L}$, or previously diagnosed diabetes [12]. The majority of participants in the ELMI study were Caucasian; therefore, we chose the waist circumference cut points for Europeans of $\geq 94 \mathrm{~cm}$ for men, $\geq 80 \mathrm{~cm}$ for women. The cohort was retrospectively assigned into the following categories at CRP completion: (1) "New onset MetS" (participants who had no MetS at baseline but had MetS at 48 months), (2) "MetS resolution" (participants who had MetS at baseline but did not have MetS at 48 months), (3) "Always MetS" (participants who had MetS at baseline and 48 months), and (4) "Never MetS" (participants who had no MetS at baseline and 48 months).

All participants underwent a baseline and a 48-month assessment that consisted of cardiovascular risk factors (lipid profile, fasting blood glucose, and BP), lifestyle (exercise capacity, leisurely exercise, and anthropometric measurements) and psychosocial parameters (perceived stress, illness intrusiveness, health-specific, and exercise selfefficacy). Body mass index (BMI) was calculated from height (in metres) and weight (in $\mathrm{kg}$ ) with participants in street clothing and shoes removed. Waist circumference was measured in $\mathrm{cm}$ at the point of maximal narrowing of the trunk viewed from the anterior position with the participant standing upright following a normal expiration [13]. Systolic and diastolic BP were measured in $\mathrm{mmHg}$ and assessed with a manual sphygmomanometer, recorded as the average of two measures taken two minutes apart after five minutes of seated rest. Fasting lipid profile (total cholesterol
(TC), HDL-C, and triglycerides) and fasting blood glucose were assessed using standard laboratory methodology [14]. Calculation of LDL-C was done using the Friedwald equation [15]. Exercise capacity was determined by a symptomlimited stress test and expressed in metabolic equivalents (METS). Health-specific self-efficacy was used to assess the participant's confidence to achieve successful lifestyle changes and was measured by a questionnaire based on the Likert scoring [16]. Perceived stress and illness intrusiveness were assessed through the Perceived Scale Rating [17] and the Illness Intrusive Rating [18] based on the Likert scoring. These questionnaires evaluate an individual's perception of stress in different situations and the perception of how their illness burden affects different aspects of their lives, respectively.

\section{Statistical Analysis}

Baseline comparisons between the groups were done with one-way ANOVA and Pearson's chi square for continuous and categorical variables, respectively. Multiple comparisons were assessed with the Tukey correction for variables that reached significance. Paired sample $t$-tests were used to compare risk factors at baseline and at 48 months within each group. Multinomial logistic regression models were used to assess for independent predictors of: (1) "New onset MetS", and (2) "MetS resolution." Age and sex were entered a priori. Variables were considered in the equation according to their association with the MetS; therefore, exercise variables such as baseline values of fitness level in metabolic equivalents, TC, LDL-C, triglycerides, HDL-C, glucose, waist circumference and BP as well as psychosocial parameters such as illness intrusiveness, perceived stress, and health-specific self-efficacy were considered. Group assignment (intervention group versus usual care group), was also entered as a variable in the equations; however, as it was not a significant contributor to our outcomes of interest, it was not included in the final models. Medication intake at baseline for statins, ACE inhibitors, calcium channel blockers, diabetes-related medications, and beta blockers (taking the medication versus not taking the medication) were also entered as variables in the equations; however, as they were not predictive of our outcomes, they were not included in the final models. Variables were removed in a backwards fashion according to their correlation to other variables in the equation and their predictive value at each step. As part of the model, special attention was placed on those variables that can be easily assessed in the health care provider's office such as anthropometric measurements, BP and psychosocial parameters such as illness intrusiveness, perceived stress, and health-specific self-efficacy. These variables were entered in the equation with age and sex, without variables that needed laboratory measurements. This was done to address our purpose to identify predictors that can be measured in the health care provider's office. These models were based on 234 participants who had complete data. The $P$ value was set at 0.05 . All data were analyzed using SPSS version 18 . 


\section{Results}

Of the 302 participants, 56 did not have outcome data at 48 months, and 12 had incomplete assessments. Those that were lost to follow-up or had an incomplete assessment were not significantly different from the participants included in the present analysis (data not shown). This resulted in a total of 234 participants who were retrospectively assigned as follows: 121, 52, 28, and 33 participants in the "Never MetS," "Always MetS," "MetS resolution" and "New onset MetS" groups, respectively. Table 1 shows baseline comparisons of demographic and cardiovascular risk factors between the groups. There were no significant differences in age, sex, family history of CVD, coronary artery bypass graft or percutaneous transluminal angiography, history of myocardial infarction, TC, LDL-C, diastolic BP, exercise capacity, leisure time physical activity, perceived stress, health-specific and exercise self-efficacy among the four groups. The "Never MetS" group had a lower proportion of participants with diabetes, lower waist circumference and BMI than the other groups, as well as higher HDL-C and lower triglycerides than the "Always MetS" and "MetS resolution" groups. The "Never MetS" group had lower fasting blood glucose than the "Always MetS" group and lower illness intrusiveness than the "MetS resolution" group. The "New onset MetS" group had a lower proportion of participants with diabetes and lower triglycerides than the "Always MetS" and "MetS resolution" group, as well as higher HDL-C, lower BMI and lower waist circumference than the "Always MetS" group. The "Always MetS" group had a higher systolic BP than the "New onset MetS" group.

Table 2 shows CVD risk factors at baseline and at 48 months for the four groups. The "Never MetS" group had an increase in HDL-C, diastolic BP and waist circumference, as well as a decrease in triglycerides, illness intrusiveness, exercise capacity, and self-reported leisure time physical activity $(P \leq 0.05)$. The "Always MetS" group had a decrease in TC, perceived stress, exercise capacity, self-reported leisure time physical activity, and exercise self-efficacy $(P \leq 0.05)$ as well as an increase in waist circumference $(P \leq 0.05)$. The "MetS resolution" group had a decrease in TC, triglycerides and self-reported leisure time physical activity $(P \leq 0.01)$ as well as an increase in HDL-C and exercise capacity $(P \leq$ 0.05). The "New onset MetS" group had a decrease in HDL$\mathrm{C}$, exercise capacity and exercise self-efficacy an increase in triglycerides, systolic and diastolic BP, and BMI and waist circumference $(P \leq 0.05)$.

Table 3 outlines the results of the multinomial logistic regression models to identify predictors for MetS onset at 48 months and MetS resolution at 48 months. All possible baseline parameters were considered; waist circumference was a significant predictor of MetS onset $\left(P \leq 0.001, R^{2}=\right.$ 0.46 ) after adjusting for age and sex. That is, an increase in waist circumference was associated with an increase in the risk of MetS. Model 2 shows the result of the logistic regression model for independent predictors of MetS resolution at 48 months. Baseline waist circumference, HDL$\mathrm{C}$ and triglycerides were independent predictors of MetS resolution after adjusting for age and sex $\left(P \leq 0.01, R^{2}=\right.$ $0.59)$. This indicates that an increase in waist circumference as well as an increase in triglycerides was associated with a greater possibility of MetS resolution, while a decrease in HDL-C was associated with a greater possibility of MetS resolution.

\section{Discussion}

Our data show that increasing waist circumference was the only significant independent predictor of MetS after adjustment for age and sex. Paradoxically, waist circumference was also an independent predictor of MetS resolution as well as decreasing HDL-C and increasing triglycerides after adjustment for age and sex. An interesting finding was that those participants that did not change their metabolic status, the "Never MetS" group and the "Always MetS" group, who represent the lowest and highest risk groups respectively, experienced a deterioration of exercise capacity and waist circumference during a four-year follow-up after CRP completion.

Waist circumference has a strong association with the metabolic syndrome cluster of abnormalities which in turn strongly correlate with the development of CVD [1921]. In those with CVD, the concomitant existence of the MetS cluster of abnormalities confers an even higher risk for cardiovascular events, cardiovascular and all-cause mortality [4-7]. Therefore, predicting the incidence of MetS in individuals with CVD is important. Our findings show that CRP graduates with an enlarged waist are at increased risk of developing MetS in the next four years such that for every $5 \mathrm{~cm}$ increase in waist circumference the risk of developing MetS in the next 48 months increased by $87.5 \%$. Together, with age and sex, this model accounted for $46 \%$ of the variation in new onset of MetS. Given that waist circumference is a component of the MetS, it is not unexpected that an enlarged waist would predict future onset of MetS. However, it is important to note that none of the other four components (triglycerides, HDL-C, fasting glucose, or $\mathrm{BP}$ ) were predictive.

The relation between waist circumference and the rest of the parameters of the metabolic syndrome is well documented; increasing values of waist circumference have been associated with increasing triglyceride levels, fasting insulin and glucose levels as well as decreasing HDL-C levels in healthy middle-aged men and women [22]. Fox et al. reported that waist circumference is highly correlated with visceral adipose tissue in both men and women $(r=$ 0.73 and $0.78, P \leq 0.001$, resp.) and, in turn, visceral adipose tissue is highly correlated with HDL-C, systolic BP, diastolic BP, and blood glucose [19]. Surprisingly, although the measurement of waist in the clinical setting has increased in the past 10 years, it is still under used in clinical practice [23]. Identifying the risk for developing MetS amongst highrisk patients is the next step to restratify this risk group. Increased waist circumference was also positively associated with a greater resolution of MetS in addition to lower HDL-C and higher triglycerides levels at baseline. This might be 
TABLE 1: Baseline comparison of demographics and cardiovascular risk factors between "Never MetS", "Always MetS", "MetS new onset" and "MetS resolution" groups.

\begin{tabular}{|c|c|c|c|c|c|c|}
\hline \multirow{2}{*}{ Risk factors at baseline } & \multicolumn{4}{|c|}{ Mean and SD and counts and percentages } & \multirow{2}{*}{$\begin{array}{l}\text { Overall } \\
P \text { value }\end{array}$} & \multirow{2}{*}{$\begin{array}{l}\text { Multiple } \\
\text { comparisons }\end{array}$} \\
\hline & $\begin{array}{c}\text { Never MetS } \\
(n=121)\end{array}$ & $\begin{array}{c}\text { Always MetS } \\
(n=52)\end{array}$ & $\begin{array}{l}\text { MetS resolution } \\
\quad(n=28)\end{array}$ & $\begin{array}{c}\text { New onset } \\
\text { MetS }(n=33)\end{array}$ & & \\
\hline Age (years) & $66.2 \pm 10.3$ & $64.5 \pm 8.3$ & $65.3 \pm 7.4$ & $62.9 \pm 7.7$ & 0.295 & - \\
\hline Sex (male) & $98(81 \%)$ & $41(79 \%)$ & $24(86 \%)$ & $29(88 \%)$ & 0.689 & - \\
\hline Family history of CVD & $40(33 \%)$ & $16(31 \%)$ & $7(25 \%)$ & $15(45 \%)$ & 0.360 & - \\
\hline $\begin{array}{l}\text { Coronary artery bypass } \\
\text { surgery }\end{array}$ & $45(37 \%)$ & $20(38 \%)$ & $8(29 \%)$ & $10(30 \%)$ & 0.723 & - \\
\hline $\begin{array}{l}\text { Percutaneous transluminal } \\
\text { coronary angiogram }\end{array}$ & $47(39 \%)$ & $14(27 \%)$ & $12(43 \%)$ & $13(39 \%)$ & 0.401 & - \\
\hline Diabetes & $8(6 \%)$ & $20(38 \%)$ & $9(32 \%)$ & $7(21 \%)$ & $<0.001$ & $\begin{array}{c}<0.001 \\
(0 \neq 1,2,3) \\
(3 \neq 1,2)\end{array}$ \\
\hline $\begin{array}{l}\text { Previous myocardial } \\
\text { infarction }\end{array}$ & $62(51 \%)$ & $24(46 \%)$ & $12(43 \%)$ & $23(69 \%)$ & 0.121 & - \\
\hline $\mathrm{TC}(\mathrm{mmol} / \mathrm{L})$ & $4.38 \pm 0.89$ & $4.66 \pm 0.99$ & $4.43 \pm 0.73$ & $4.48 \pm 0.74$ & 0.282 & - \\
\hline LDL-C $(\mathrm{mmol} / \mathrm{L})$ & $2.53 \pm 0.73$ & $2.59 \pm 0.81$ & $2.44 \pm 0.58$ & $2.68 \pm 0.62$ & 0.582 & - \\
\hline $\mathrm{HDL}-\mathrm{C}(\mathrm{mmol} / \mathrm{L})$ & $1.25 \pm 0.31$ & $0.99 \pm 0.22$ & $1.01 \pm 0.20$ & $1.17 \pm 0.28$ & $<0.001$ & $\begin{array}{c}<0.001(0 \neq 1,2) \\
0.024(1 \neq 3)\end{array}$ \\
\hline Triglycerides (mmol/ L) & $1.32 \pm 0.66$ & $2.37 \pm 0.84$ & $2.15 \pm 1.11$ & $1.38 \pm 0.50$ & $<0.001$ & $\begin{array}{l}<0.001(0 \neq 1,2) \\
<0.001(3 \neq 1,2)\end{array}$ \\
\hline $\begin{array}{l}\text { Fasting blood glucose } \\
(\mathrm{mmol} / \mathrm{L})\end{array}$ & $5.32 \pm 1.58$ & $6.34 \pm 1.41$ & $5.99 \pm 1.18$ & $5.86 \pm 1.30$ & $<0.001$ & $<0.001(0 \neq 1)$ \\
\hline Systolic BP (mmHg) & $126 \pm 22$ & $134 \pm 17$ & $130 \pm 27$ & $120 \pm 14$ & 0.024 & $0.020(1 \neq 3)$ \\
\hline Diastolic BP (mmHg) & $71 \pm 10$ & $75 \pm 10$ & $72 \pm 13$ & $73 \pm 10$ & 0.154 & - \\
\hline Body mass index $\left(\mathrm{kg} / \mathrm{m}^{2}\right)$ & $25.4 \pm 2.9$ & $30.4 \pm 4.2$ & $28.6 \pm 3.9$ & $27.6 \pm 3.1$ & $<0.001$ & $\begin{array}{c}(0 \neq 1,2,3) \\
<0.002(1 \neq 3) \\
<0.001\end{array}$ \\
\hline Waist circumference $(\mathrm{cm})$ & $86.7 \pm 9.0$ & $102.4 \pm 11.5$ & $99.8 \pm 11.0$ & $95.6 \pm 9.1$ & $<0.001$ & $\begin{array}{c}(0 \neq 1,2,3) \\
0.013(1 \neq 3)\end{array}$ \\
\hline Exercise capacity (METS) & $10.8 \pm 4.4$ & $9.1 \pm 2.2$ & $13.8 \pm 2.9$ & $10.7 \pm 2.3$ & 0.109 & - \\
\hline $\begin{array}{l}\text { Leisure time physical } \\
\text { activity (kcal/week) }\end{array}$ & $3029 \pm 337$ & $2837 \pm 1708$ & $3090 \pm 558$ & $3219 \pm 226$ & 0.894 & - \\
\hline Perceived stress & $32 \pm 8$ & $31 \pm 8$ & $34 \pm 9$ & $32 \pm 6$ & 0.512 & - \\
\hline Illness intrusiveness & $27 \pm 11$ & $33 \pm 16$ & $36 \pm 19$ & $28 \pm 13$ & 0.020 & $0.040(0 \neq 2)$ \\
\hline Health-specific self-efficacy & $43 \pm 4$ & $42 \pm 4$ & $42 \pm 6$ & $41 \pm 4$ & 0.064 & - \\
\hline Exercise self-efficacy & $67 \pm 12$ & $70 \pm 10$ & $63 \pm 13$ & $64 \pm 12$ & 0.080 & - \\
\hline
\end{tabular}

CVD: cardiovascular disease, TC: total cholesterol, LDL-C: low density lipoprotein cholesterol, HDL-C: high-density lipoprotein cholesterol.

One-way ANOVA and Pearson's chi square for continuous and categorical variables, respectively. Multiple comparisons were assessed with the Tukey correction. Multiple comparisons: 0: Never MetS, 1: Always MetS, 2: MetS resolution, 3: New onset MetS.

Note: $0 \neq 1$ means that Never MetS is significantly different with Always MetS group.

explained in part by the patient's higher drive to improve their risk factor profile by a perception of a higher degree of disease burden. However, given that we did not observe improvements in anthropometric measurements, exercise capacity or psychosocial variables, which would be reflective of changes in lifestyle, it is possible that the higher-risk factor levels may have resulted in the patients being more readily identified for pharmacological treatment, with a higher proportion of high-risk patients being on lipid-lowering medications (data not shown). This is reflected by the finding that the "MetS resolution" group experienced improvements of TC, HDL-C, and triglycerides without any improvement in waist circumference. It is important to mention that having an enlarged waist at CRP completion and a decreased waist at 48 months is what defined the "MetS resolution" group; therefore, it is not surprising to find that waist circumference was associated with MetS resolution. The fact that an increased waist circumference was also associated 
TABLE 2: CVD risk factors at baseline and at 48 months for "Never MetS," "Always MetS," "MetS new onset" and "MetS resolution" groups.

\begin{tabular}{|c|c|c|c|c|c|c|c|c|}
\hline \multirow{2}{*}{ CVD risk factors } & \multicolumn{2}{|c|}{ Never MetS $(n=121)$} & \multicolumn{2}{|c|}{ Always MetS $(n=52)$} & \multicolumn{2}{|c|}{ MetS resolution $(n=28)$} & \multicolumn{2}{|c|}{ New Onset MetS $(n=33)$} \\
\hline & Baseline & 48 months & Baseline & 48 months & Baseline & 48 months & Baseline & 48 months \\
\hline $\mathrm{TC}(\mathrm{mmol} / \mathrm{L})$ & $4.39 \pm 0.90$ & $4.32 \pm 0.90$ & $4.67 \pm 0.99$ & $4.40 \pm 0.95^{\ddagger}$ & $4.43 \pm 0.73$ & $4.07 \pm 0.77^{\ddagger}$ & $4.51 \pm 0.74$ & $4.55 \pm 0.83$ \\
\hline LDL-C (mmol/L) & $2.52 \pm 0.74$ & $2.48 \pm 0.76$ & $2.57 \pm 0.80$ & $2.41 \pm 0.69$ & $2.45 \pm 0.59$ & $2.29 \pm 0.66$ & $2.71 \pm 0.62$ & $2.64 \pm 0.71$ \\
\hline $\mathrm{HDL}-\mathrm{C}(\mathrm{mmol} / \mathrm{L})$ & $1.24 \pm 0.30$ & $1.30 \pm 0.36^{\dagger}$ & $0.99 \pm 0.22$ & $0.98 \pm 0.21$ & $1.01 \pm 0.20$ & $1.18 \pm 0.26^{\dagger}$ & $1.17 \pm 0.28$ & $1.09 \pm 0.27^{\S}$ \\
\hline Triglycerides $(\mathrm{mmol} / \mathrm{L})$ & $1.32 \pm 0.67$ & $1.18 \pm 0.60^{\ddagger}$ & $2.37 \pm 0.85$ & $2.34 \pm 2.20$ & $2.16 \pm 1.11$ & $1.30 \pm 0.50^{*}$ & $1.38 \pm 0.51$ & $1.79 \pm 0.84^{\dagger}$ \\
\hline $\begin{array}{l}\text { Fasting blood glucose } \\
(\mathrm{mmol} / \mathrm{L})\end{array}$ & $5.3 \pm 1.6$ & $5.3 \pm 0.8$ & $6.33 \pm 1.42$ & $6.67 \pm 1.47$ & $5.9 \pm 1.2$ & $5.6 \pm 0.7$ & $5.7 \pm 1.2$ & $6.2 \pm 1.4$ \\
\hline Systolic BP (mmHg) & $126 \pm 21$ & $127 \pm 21$ & $134 \pm 17$ & $134 \pm 17$ & $130 \pm 27$ & $122 \pm 17$ & $120 \pm 14$ & $131 \pm 14^{\dagger}$ \\
\hline Diastolic BP (mmHg) & $71 \pm 10$ & $74 \pm 12^{\dagger}$ & $75 \pm 10$ & $77 \pm 9$ & $72 \pm 13$ & $71 \pm 9$ & $73 \pm 10$ & $79 \pm 10^{\dagger}$ \\
\hline $\begin{array}{l}\text { Body mass index } \\
\left(\mathrm{kg} / \mathrm{m}^{2}\right)\end{array}$ & $25.4 \pm 2.9$ & $25.6 \pm 3.5$ & $30.4 \pm 4.2$ & $30.7 \pm 4.5$ & $28.6 \pm 3.8$ & $28.3 \pm 4.5$ & $27.6 \pm 3.0$ & $29.1 \pm 3.7^{*}$ \\
\hline $\begin{array}{l}\text { Waist circumference } \\
(\mathrm{cm})\end{array}$ & $86.7 \pm 8.9$ & $88.6 \pm 10.9^{*}$ & $102.4 \pm 11.5$ & $104.7 \pm 12.8^{\ddagger}$ & $99.8 \pm 11.1$ & $99.0 \pm 12.2$ & $95.6 \pm 9.1$ & $100.9 \pm 10.9^{*}$ \\
\hline $\begin{array}{l}\text { Exercise capacity } \\
\text { (METs) }\end{array}$ & $10.6 \pm 2.4$ & $10.0 \pm 2.7^{\dagger}$ & $9.5 \pm 2.1$ & $8.9 \pm 2.3^{\dagger}$ & $14.8 \pm 22.5$ & $17.4 \pm 36.8$ & $10.6 \pm 2.3$ & $10.1 \pm 2.4^{\ddagger}$ \\
\hline $\begin{array}{l}\text { Leisure time physical } \\
\text { activity (kcal/week) }\end{array}$ & $2985 \pm 2225$ & $2230 \pm 1828^{*}$ & $2773 \pm 1616$ & $2247 \pm 2104^{\ddagger}$ & $3066 \pm 1538$ & $1786 \pm 1042^{\dagger}$ & $2784 \pm 19778$ & $2198 \pm 3011$ \\
\hline Perceived stress & $32 \pm 7$ & $32 \pm 8$ & $32 \pm 8$ & $31 \pm 8$ & $34 \pm 9$ & $33 \pm 10$ & $33 \pm 6$ & $31 \pm 5$ \\
\hline Illness intrusiveness & $27 \pm 11$ & $24 \pm 11^{\ddagger}$ & $33 \pm 14$ & $30 \pm 14$ & $35 \pm 19$ & $31 \pm 16$ & $28 \pm 15$ & $27 \pm 15$ \\
\hline $\begin{array}{l}\text { Health-specific } \\
\text { self-efficacy }\end{array}$ & $43 \pm 4$ & $43 \pm 4$ & $42 \pm 4$ & $42 \pm 4$ & $42 \pm 5$ & $42 \pm 4$ & $41 \pm 4$ & $40 \pm 4$ \\
\hline Exercise self-efficacy & $67 \pm 12$ & $64 \pm 14$ & $70 \pm 10$ & $63 \pm 15^{*}$ & $65 \pm 11$ & $58 \pm 16$ & $64 \pm 13$ & $58 \pm 14^{\ddagger}$ \\
\hline
\end{tabular}

$* P \leq 0.001$.

${ }^{\dagger} P \leq 0.01$.

${ }^{\ddagger} P \leq 0.05$.

Paired sample $t$-tests.

Total cholesterol, LDL-C: low density lipoprotein cholesterol, HDL-C: high density lipoprotein cholesterol, and BP: blood pressure.

with MetS onset over 48 months indicates the importance of managing these patients effectively whether through lifestyle changes orpharmaco therapy to reduce their future risk of CVD.

While not directly associated with our primary question, an interesting finding was that patients in either the "Never MetS" or "Always MetS" had a decrease in exercise capacity and an increase in waist circumference. This is comparable to the general CRP population, where it has been reported that adherence to favourable lifestyle behaviours decrease shortly after CRP completion [24]. This may reflect the challenges that both, the patients and the physicians have to successfully manage cardiovascular risk factors through behavioural changes [25-27]. Lifestyle changes are essential in the management and prevention of the MetS [28], and associated complications such as diabetes [29] and cardiovascular events [30]. The "New onset MetS" group had an increase in BP, anthropometric measurements and triglycerides and a decrease in HDL-C, exercise capacity and exercise self-efficacy. Furthermore, the highest risk group, "Always MetS," as well as the lowest risk group, "Never MetS," experienced both an increase in waist circumference and a decrease in exercise capacity, which in turn reflects deterioration of lifestyle behaviours. The importance of maintaining healthy lifestyle behaviours is vastly documented. Myers et al. reported that an improvement of 1 MET in exercise capacity (defined as $3.5 \mathrm{~mL} \mathrm{O} 2 / \mathrm{Kg} / \mathrm{min}$ ) provides a $12 \%$ reduction in all-cause mortality in healthy men [30], and an $18 \%$ reduction in all-cause mortality in men with diabetes [31]. Our results highlight the failure of most patients to maintain positive behavioural changes, even after a CRP. This is an important caveat that needs to be addressed in order to prevent the appearance of MetS in patients with CVD and in the long-term management of patients after CRP.

\section{Study Limitations}

As the groups were retrospectively assigned, we cannot exclude the possibility of a bias in the group assignment. Also the ELMI Trial was not designed to prospectively assess incident MetS. However, our findings, supported by the results of previous studies do suggest that the assessment of waist circumference in a high-risk population can help physicians identify those at greatest risk. We must also acknowledge that our study population, namely, patients completing a CRP, may not be representative of the general population of CVD patients. However, we have no reason to believe that waist circumference would be any less important in patients not attending a CRP. Lastly, we assessed the predictors of MetS resolution and incidence in a cohort primarily of European descent, and our results may not be applicable to other ethnic groups. 
TABLE 3: Multinomial regression models for independent predictors of "New onset MetS" 48 months (Model 1) and for independent predictors of "MetS Resolution" (Model 2) following cardiac rehabilitation.

\begin{tabular}{|c|c|c|c|}
\hline \multirow[b]{2}{*}{ Variables } & \multicolumn{2}{|c|}{ Model $1\left(R^{2}=0.46\right)$} & \multirow[b]{2}{*}{$P$ value } \\
\hline & Odds ratio & $\begin{array}{c}95 \% \text { confidence } \\
\text { interval }\end{array}$ & \\
\hline Age (years) & 0.971 & $0.927-1.018$ & 0.220 \\
\hline Sex & 0.187 & $0.043-0.823$ & 0.027 \\
\hline $\begin{array}{l}\text { Waist } \\
\text { circumference } \\
(\mathrm{cm})\end{array}$ & 1.175 & $1.102-1.253$ & $\leq 0.001$ \\
\hline \multicolumn{4}{|c|}{ Model $2\left(R^{2}=0.59\right)$} \\
\hline Age (years) & 1.027 & $0.966-1.092$ & 0.396 \\
\hline Sex & 0.030 & $0.004-0.202$ & $\leq 0.001$ \\
\hline $\begin{array}{l}\text { Waist } \\
\text { circumference } \\
(\mathrm{cm})\end{array}$ & 1.234 & $1.145-1.330$ & $\leq 0.001$ \\
\hline HDL-C (mmol/L) & 0.027 & $0.002-0.344$ & 0.005 \\
\hline $\begin{array}{l}\text { Triglycerides } \\
(\mathrm{mmol} / \mathrm{L})\end{array}$ & 3.005 & $1.465-6.166$ & 0.003 \\
\hline
\end{tabular}

Multinomial logistic regression models.

\section{Conclusion}

Over a four-year follow-up period, an increasing waist circumference is the only independent predictor of future MetS in patients with CVD. Likewise, an increasing waist was also a predictor of MetS resolution, as were increasing triglyceride levels and decreasing HDL-C. These findings strengthen the notion that patients with CVD with an enlarged waist at CRP completion are at risk of further cardiometabolic deterioration. Our results highlight the clinical importance of waist circumference for identifying and restratifying high-risk patients. Waist measurement is readily available to identify individuals at the highest riskthose with CVD at risk of future MetS. A cautionary note is that patients who did not have MetS at baseline or at 48 months still experienced an increase in waist circumference and a decrease in exercise capacity. This also occurred in patients with the MetS at baseline who still met the criteria at 48 months, indicating that both the lowest and highest risk patients are susceptible to those adverse changes and need to be regularly assessed and appropriately managed. Traditionally, the MetS has been used to assess the risk of future CVD and diabetes, whereas our study has the strength of considering the MetS and its synergistic effect with CVD as an endpoint that confers high cardiometabolic risk, and therefore, should be prevented. Our data show that waist circumference is a predictor of both, MetS onset and resolution; therefore, those patients with CVD and an enlarged waist need further risk factor management and follow-up. These results provide further data on patients with CVD at risk of MetS. An extension of CRP and/or acloser follow-up after CRP completion for patients with CVD and an enlarged waist would be a practical intervention that may improve quality of care.

\section{List of Abbreviations}

$\begin{array}{ll}\text { MetS: } & \text { Metabolic syndrome } \\ \text { CVD: } & \text { Cardiovascular disease } \\ \text { CRP: } & \text { Cardiac rehabilitation programs } \\ \text { BP: } & \text { Blood pressure } \\ \text { TC: } & \text { Total cholesterol } \\ \text { HDL-C: } & \text { High density lipoprotein cholesterol } \\ \text { LDL-C: } & \text { Low density lipoprotein cholesterol } \\ \text { HR: } & \text { Hazard ratio } \\ \text { ELMI Trial: } & \text { Extensive Lifestyle Management } \\ & \text { Intervention Trial } \\ \text { BMI: } & \text { Body mass index } \\ \text { METS: } & \text { Metabolic equivalents. }\end{array}$

\section{Authors' Contribution}

Each author contributed in the study design, data analysis, interpretation and paper writing.

\section{Conflict of Interests}

The authotrs declare that they have no conflict of interests.

\section{References}

[1] S. M. Grundy, J. I. Cleeman, S. R. Daniels et al., "Diagnosis and management of the metabolic syndrome: an American Heart Association/National Heart, Lung, and Blood Institute scientific statement-executive summary," Critical Pathways in Cardiology, vol. 4, no. 4, pp. 198-203, 2005.

[2] E. S. Ford, "Risks for all-cause mortality, cardiovascular disease, and diabetes associated with the metabolic syndrome: a summary of the evidence," Diabetes Care, vol. 28, no. 7, pp. 1769-1778, 2005.

[3] P. Zimmet, D. Magliano, Y. Matsuzawa, G. Alberti, and J. Shaw, "The metabolic syndrome: a global public health problem and a new definition," Journal of Atherosclerosis and Thrombosis., vol. 12, no. 6, pp. 295-300, 2005.

[4] B. Hu, Y. Zhou, Y. Liu et al., "Impact of metabolic syndrome on clinical outcomes after drug-eluting stent implantation in patients with coronary artery disease," Angiology, vol. 62, no. 6, pp. 440-446, 2011.

[5] K. J. Hunt, R. G. Resendez, K. Williams, S. M. Haffner, and M. P. Stern, "National Cholesterol Education Program versus World Health Organization metabolic syndrome in relation to all-cause and cardiovascular mortality in the San Antonio heart study," Circulation, vol. 110, no. 10, pp. 1251-1257, 2004.

[6] O. C. Marroquin, K. E. Kip, D. E. Kelley et al., "Metabolic syndrome modifies the cardiovascular risk associated with angiographic coronary artery disease in women: a report from the Women's ischemia syndrome evaluation," Circulation, vol. 109, no. 6, pp. 714-721, 2004.

[7] S. S. Anand, Q. Yi, H. Gerstein et al., "Relationship of metabolic syndrome and fibrinolytic dysfunction to cardiovascular disease," Circulation, vol. 108, no. 4, pp. 420-425, 2003.

[8] C. J. Lavie and R. V. Milani, "Cardiac rehabilitation and exercise training programs in metabolic syndrome and diabetes," Journal of Cardiopulmonary Rehabilitation, vol. 25, no. 2, pp. 59-66, 2005. 
[9] G. J. Balady, M. A. Williams, P. A. Ades et al., "Core components of cardiac rehabilita tion/secondary prevention programs: 2007 update: a scientific statement from the American Heart Association Exercise, Cardiac Rehabilitation, and Prevention Committee, the Council on Clinical Cardiology; the Councils on Cardiovascular Nursing, Epidemiology and Prevention, and Nutrition, Physical Activity, and Metabolism; and the American Association of Cardiovascular and Pulmonary Rehabilitation," Circulation, vol. 115, no. 20, pp. 2675-2682, 2007.

[10] P. D. Savage, J. A. Banzer, G. J. Balady, and P. A. Ades, "Prevalence of metabolic syndrome in cardiac rehabilitation/secondary prevention programs," American Heart Journal, vol. 149, no. 4, pp. 627-631, 2005.

[11] S. A. Lear, J. J. Spinelli, W. Linden et al., "The Extensive Lifestyle Management Intervention (ELMI) after cardiac rehabilitation: a 4-year randomized controlled trial," American Heart Journal, vol. 152, no. 2, pp. 333-339, 2006.

[12] K. G. M. M. Alberti, R. H. Eckel, S. M. Grundy et al., "Harmonizing the metabolic syndrome: a joint interim statement of the international diabetes federation task force on epidemiology and prevention; National heart, lung, and blood institute; American heart association; World heart federation; International atherosclerosis society; And international association for the study of obesity," Circulation, vol. 120, no. 16, pp. 1640-1645, 2009.

[13] C. W. Callaway, W. C. Chumlea, C. Bouchard et al., "Circumferences," in Anthropometric Standardization Reference Manual, pp. 39-54, Human Kinetics, Champaign, Ill, USA, 1998.

[14] C. McGuinness, D. W. Seccombe, J. J. Frohlich, C. Ehnholm, J. Sundvall, and G. Steiner, "Laboratory standardization of a large international clinical trial: the DAIS experience," Clinical Biochemistry, vol. 33, no. 1, pp. 15-24, 2000.

[15] W. T. Friedewald, R. I. Levy, and D. S. Fredrickson, "Estimation of the concentration of low-density lipoprotein cholesterol in plasma, without use of the preparative ultracentrifuge," Clinical Chemistry, vol. 18, no. 6, pp. 499-502, 1972.

[16] R. Schwarzer, "Measurement of perceived self-efficacy," Tech. Rep., Open University Press, 1995.

[17] M. W. Linn, "Modifiers and perceived stress scale," Journal of Consulting and Clinical Psychology, vol. 54, no. 4, pp. 507-513, 1986.

[18] G. M. Devins, "Illness intrusiveness and the psychosocial impact of lifestyle disruptions in chronic life-threatening disease," Advances in Renal Replacement Therapy, vol. 1, no. 3, pp. 251-263, 1994.

[19] C. S. Fox, J. M. Massaro, U. Hoffmann et al., "Abdominal visceral and subcutaneous adipose tissue compartments: association with metabolic risk factors in the framingham heart study," Circulation, vol. 116, no. 1, pp. 39-48, 2007.

[20] T. Hayashi, E. J. Boyko, D. L. Leonetti et al., "Visceral adiposity is an independent predictor of incident hypertension in Japanese Americans," Annals of Internal Medicine, vol. 140, no. 12, pp. 992-1000, 2004.

[21] L. E. Wagenknecht, C. D. Langefeld, A. L. Scherzinger et al., "Insulin sensitivity, insulin secretion, and abdominal fat: the Insulin Resistance Atherosclerosis Study (IRAS) family study," Diabetes, vol. 52, no. 10, pp. 2490-2496, 2003.

[22] M. C. Pouliot, J. P. Despres, S. Lemieux et al., "Waist circumference and abdominal sagittal diameter: best simple anthropometric indexes of abdominal visceral adipose tissue accumulation and related cardiovascular risk in men and women," American Journal of Cardiology, vol. 73, no. 7, pp. 460-468, 1994.
[23] S. C. Smith and D. Haslam, "Abdominal obesity, waist circumference and cardiometabolic risk: awareness among primary care physicians, the general population and patients at riskthe shape of the nations survey," Current Medical Research and Opinion, vol. 23, no. 1, pp. 29-47, 2007.

[24] S. M. Moore, C. M. Ruland, F. J. Pashkow, and G. G. Blackburn, "Women's patterns of exercise following cardiac rehabilitation," Nursing Research, vol. 47, no. 6, pp. 318-324, 1998.

[25] "Clinical guidelines on the identification, evaluation, and treatment of overweight and obesity in adults - the evidence report, National Institutes of Health," Obesity Research, vol. 6, supplement 2, pp. 51S-209S, 1998.

[26] D. A. Anderson and T. A. Wadden, "Treating the obese patient suggestions for primary care practice," Archives of Family Medicine, vol. 8, no. 2, pp. 156-167, 1999.

[27] N. A. King, P. Caudwell, M. Hopkins et al., "Metabolic and behavioral compensatory responses to exercise interventions: barriers to weight loss," Obesity, vol. 15, no. 6, pp. 1373-1383, 2007.

[28] V. Mujica, A. Urzúa, E. Leiva et al., "Intervention with education and exercise reverses the metabolic syndrome in adults," Journal of the American Society of Hypertension, vol. 4, no. 3, pp. 148-153, 2010.

[29] W. C. Knowler, E. Barrett-Connor, S. E. Fowler et al., "Reduction in the incidence of type 2 diabetes with lifestyle intervention or metformin," The New England Journal of Medicine, vol. 346, no. 6, pp. 393-403, 2002.

[30] J. Myers, M. Prakash, V. Froelicher, D. Do, S. Partington, and J. Edwin Atwood, "Exercise capacity and mortality among men referred for exercise testing," The New England Journal of Medicine, vol. 346, no. 11, pp. 793-801, 2002.

[31] E. S. Nylen, P. Kokkinos, J. Myers, and C. Faselis, "Prognostic effect of exercise capacity on mortality in older adults with diabetes mellitus," Journal of the American Geriatrics Society, vol. 58, no. 10, pp. 1850-1854, 2010. 


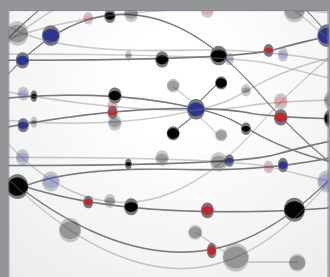

The Scientific World Journal
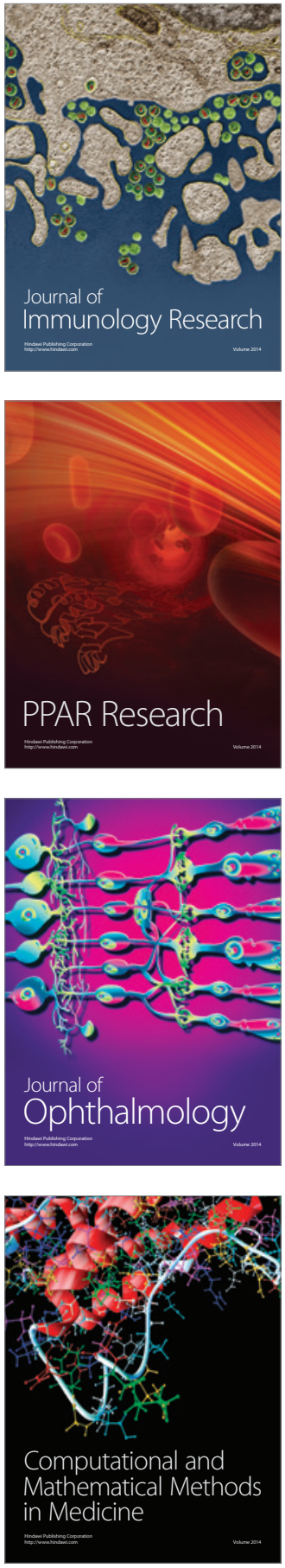

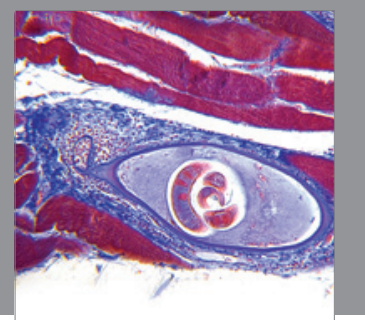

Gastroenterology

Research and Practice
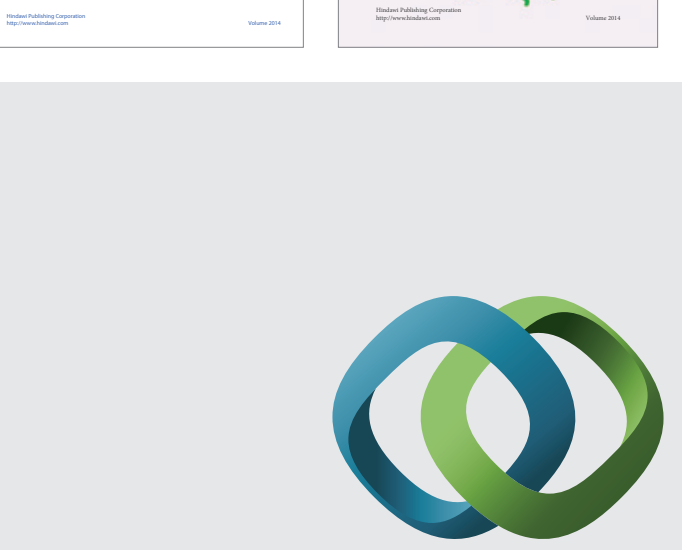

\section{Hindawi}

Submit your manuscripts at

http://www.hindawi.com
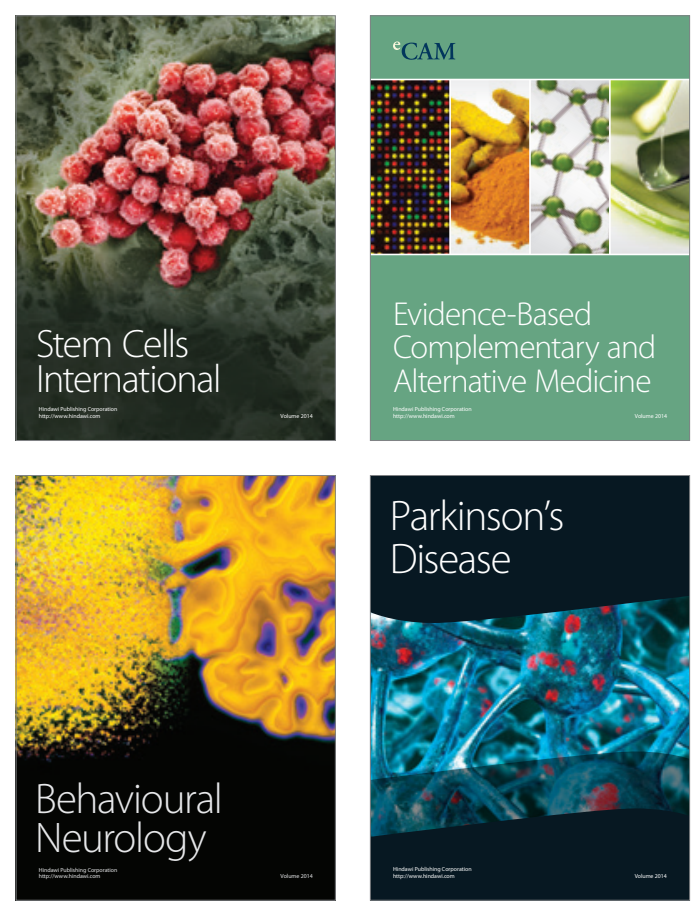

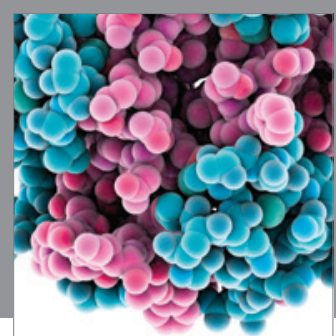

Journal of
Diabetes Research

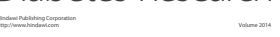

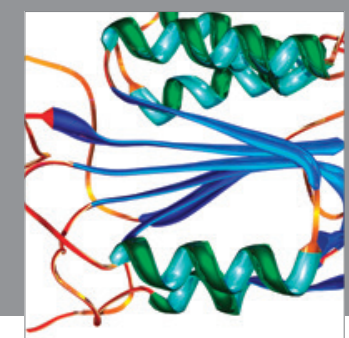

Disease Markers
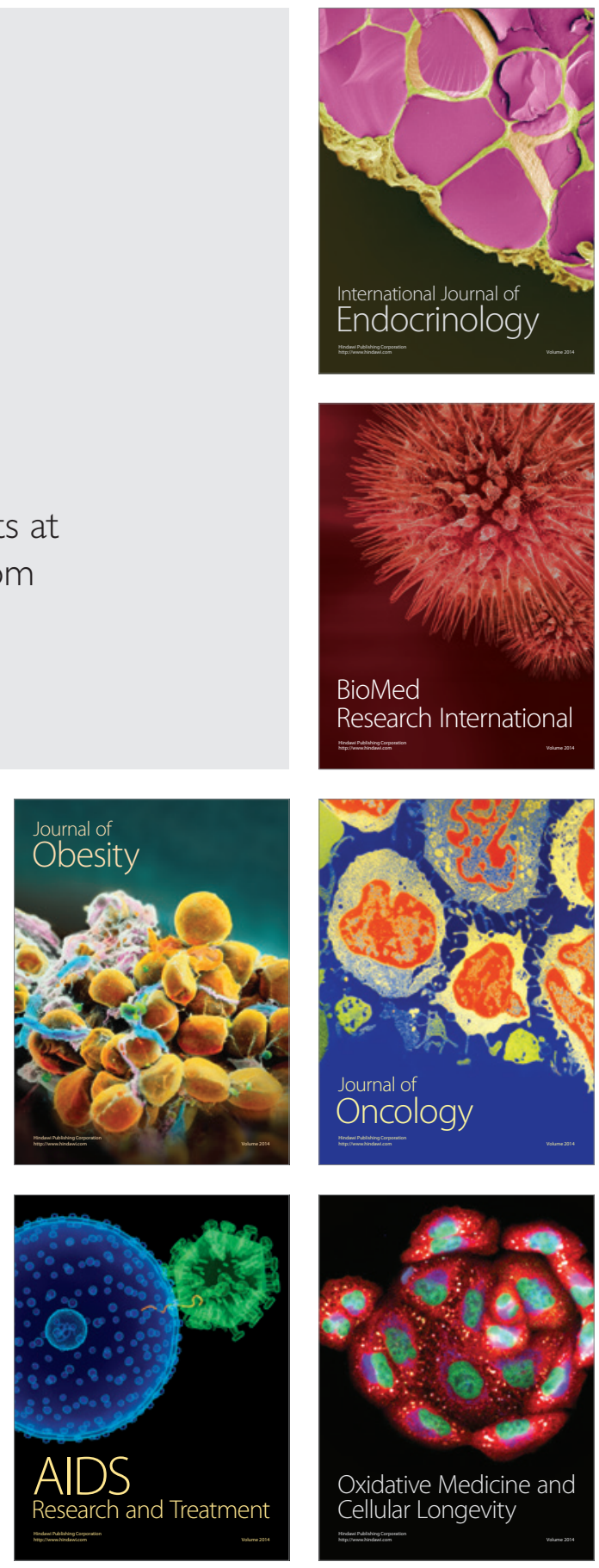